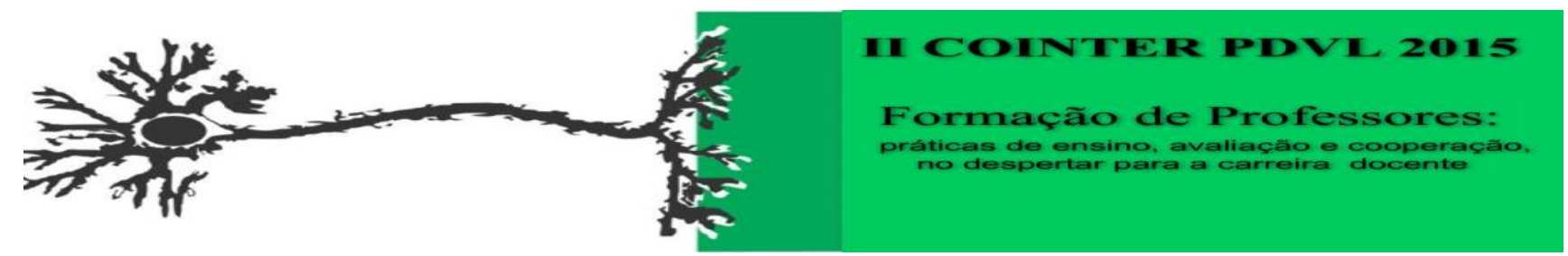

\title{
PROBLEMAS DO COTIDIANO NO ENSINO DE MATEMÁTICA: USO DAS OPERAÇÕES FUNDAMENTAIS
}

\author{
Apresentação: Pôster
}

\begin{abstract}
Antonio Kennedy Lopes Dantas ${ }^{1}$; Manassés da Silva Batista ${ }^{2}$; João Alves da Silva ${ }^{3}$; Franscismar Holanda ${ }^{4}$
\end{abstract}

\section{Introdução}

Os métodos inovadores são apresentados como uma tendência metodológica no ensino da matemática, os quais fundamentam a pratica do professor e facilitam a aprendizagem do aluno, no entanto, ainda não foram adotados amplamente pelos professores da rede publica, e estas estratégias devem ser consideradas como uma ferramenta fundamental na pratica do professor.

Os métodos inovadores de matemática no ensino fundamental têm como principal objetivo trazer aos alunos uma compreensão mais fácil os conteúdos abordado pelo professor em sala de aula, que são entendidos como estratégias para a aprendizagem. Oferecendo contribuições que vão possibilitando maior rendimento no aprendizado.

Este trabalho visa melhorar o ensino e a aprendizagem das operações fundamentais de maneira mais interessante envolvendo o dia a dia do discente através do uso de materiais concretos como simulação de compras e vendas em supermercados com cédulas artificiais, aonde os alunos tiveram que exercitar conceitos de soma, subtração, multiplicação e divisão, fazendo com que os mesmos entendam a importância do uso das operações fundamentais no ensino de matemática, atribuindo uma melhor compreensão aos alunos. Sabemos que o ensino só se torna motivador quando existe uma curiosidade do aluno em conhecer o novo.

[...]Ao aluno deve ser dado o direito de aprender. Não um 'aprender' mecânico, repetitivo, de fazer sem saber o que faz e por que faz. Muito

\footnotetext{
${ }^{1}$ Matemática, IFPI, Brasil. E-mail: kennedylopesdantas@hotmail.com

${ }^{2}$ Matemática, IFPI, Brasil. E-mail: manassess923@gmail.com

${ }^{3}$ Matemática, IFPI, Brasil. E-mail: johnetomiths@gmail.com

${ }^{4}$ Mestrado, IFPI, Brasil. E-mail: frholanda@ifpi.edu.br
} 
menos um 'aprender' que se esvazia em brincadeiras. Mas um aprender significativo do qual o aluno participe raciocinando, compreendendo, reelaborando o saber historicamente produzido e superando, assim, sua visão ingênua, fragmentada e parcial da realidade (FIORENTINI; MIORIN, 2004, p.62).

A matemática é uma ciência que precisa ser trabalhada detalhadamente em sala de aula com o propósito de conseguirmos atingir os objetivos, objetivos estes que não ocorram somente com metodologias repetitivas de forma mecanizada sem planejamento, assim trabalhar a matemática durante as resoluções de problemas é fazer com que os alunos vão além das próprias soluções, ou seja, este método pedagógico faz com que os alunos se sintam desafiados e busquem novas estratégias para tais soluções de modo organizado e dinâmico obtendo com isso uma aprendizagem significativa que os preparam para a vida.

\section{Fundamentação Teórica}

O ensino aprendizagem da matemática sofreu muitas mudanças ao decorrer dos anos. É necessário conhecer a fundamentação da mesma e usá-la corretamente. Então se propõe uma reflexão sobre a necessidade de se utilizar metodologias diversificadas na tentativa de reverter o cenário de aversão à matemática que provavelmente surge nas séries iniciais do ensino fundamental.

Assim acredita-se que através desses materiais concretos é possível desenvolver o conhecimento matemático, onde o discente possa interagir com esse conhecimento, uma vez que constituem também um meio de transmitir mensagens capazes de resgatar a auto-estima, os valores como solidariedade, responsabilidade, disciplina, autoconfiança, auto aceitação, tolerância, concentração e alegria.

Para Boyer "A Matemática originalmente surgiu como parte da vida diária do homem, e se há validade no principio biológico da sobrevivência dos mais aptos à persistência da raça humana provavelmente tem relação com o desenvolvimento de conceitos matemáticos.” (1974, p.15).

A matemática vem evoluindo de acordo com o tempo e da mesma maneira as suas didáticas pedagógicas, desenvolvendo novas maneiras de raciocínio lógico e diversificando as metodologias utilizadas no ensino da mesma. 
[...]É importante destacar que a Matemática deverá ser vista pelo aluno como um conhecimento que pode favorecer o desenvolvimento do seu raciocínio, de sua sensibilidade expressiva, de sua sensibilidade estética e de sua imaginação. (BRASIL, 1997, p. 125).

É percebível que o uso de materiais concretos não constitui a aprendizagem em si, mas é um excelente meio que permite o diagnóstico, a intervenção e até mesmo a transmissão de conteúdos conceituais e procedimentais sem que o discente perceba.

[...]E somos, então, levados a atacar diretamente a estrutura de todo o ensino, em particular, o ensino da matemática, mudando completamente a ênfase do conteúdo da quantidade de conhecimentos que a criança adquira, para uma ênfase na metodologia que desenvolva atitude, que desenvolva capacidade de matematizar situações reais, capacidade de criar teorias adequadas para as situações mais diversas [...] (D’AMBRÓSIO, 1986, p.14-15).

Contudo se torna fácil dizer que a matemática está presente em todas as nossas atividades e que sem ela é impossível viver. A matemática é uma das áreas de ampla estrutura para um empenho de conhecimentos e interesses estudantis.

A aprendizagem contextualizada preconizada pelos Parâmetros Curriculares Nacionais (PCNs) visa que o aluno aprenda a mobilizar competências para solucionar problemas com contextos apropriados, de maneira a ser capaz de transferir essa capacidade de resolução de problemas para os contextos do mundo social e, especialmente, do mundo produtivo. Em matemática, a contextualização é um instrumento bastante útil, desde que interpretada numa abordagem mais ampla e não empregada de modo artificial e forçado, e que não se restrinja apenas ao cotidiano do aluno.

\section{Metodologia}

A pesquisa foi desenvolvida com alunos do $5^{\circ}$ ano do ensino fundamental em uma escola pública municipal do município de Teresina Piauí situada no nordeste do Piauí onde a mesma é capital do estado.

Foram quatro etapas, sendo que na primeira etapa foram realizadas aulas expositivas utilizando recursos de vídeo-aulas.

$\mathrm{Na}$ segunda etapa foram realizados levantamentos qualitativos e quantitativos exploratórios e analíticos, utilizando atividades diagnosticas e matematizadas que enfatizavam problemas 
envolvendo as quatro operações do nosso cotidiano. Na aplicação de atividades procuramos verificar como anda o desenvolvimento dos alunos envolvendo essas situações problema.

$\mathrm{Na}$ terceira etapa foram realizadas atividades onde os alunos foram separados em grupos para simularem uma feira, ou supermercado, ou até mesmo ostras experiência vivenciada no seu cotidiano onde os alunos tinham que manipular as quatro operações através da simulação de compra e venda de mercadorias com cédulas artificiais.

$\mathrm{Na}$ quarta e ultima etapa foi aplicado questionários com o professor e com os alunos para verificar a efetividade da aplicação de métodos inovadores no ensino da matemática.

\section{Resultados e Discussões}

Na primeira etapa houve uma aplicação de teste de conhecimentos básicos pra os alunos resolverem problemas que envolvessem situações de raciocínio e utilizassem as operações fundamentais.

De acordo com os resultados obtidos pudemos concluir que $15 \%$ dos alunos tiveram um bom desempenho na resolução das questões. Outra parte de $60 \%$ dos alunos tiveram dificuldade em entender a pergunta e diferenciar se era uma adição, subtração, multiplicação ou divisão. Já o restante da sala, os outros $25 \%$ já não conseguiram nem sequer calcular corretamente.

$\mathrm{Na}$ segunda etapa houve uma pequena revisão sobre o assunto, com explicação das propriedades e com exemplos para uma melhor absorção do conteúdo para os alunos.

$\mathrm{Na}$ terceira etapa foi lançada uma atividade pós-teste, onde já haviam questões mais complicadas, mas com os mesmos objetivos de desenvolver o raciocínio e fazer com os alunos utilizam as operações para resolver problemas que envolvam situações do nosso dia-a-dia.

Já no teste final pudemos observar que os alunos já montavam os problemas com mais clareza, de acordo com as respostas desse teste podemos concluir que houve um rendimento de $80 \%$ dos alunos em seu conhecimento. Dentro da atividade proposta analisamos que $83 \%$ dos alunos conseguiram obter bom desempenho. Já os 17\% apresentaram dificuldade em calcular os problemas obtidos pelo enunciado da questão.

De acordo com o nosso propósito de trabalho pudemos considerar que a aplicação de conteúdo envolvendo os problemas e situações diários, pode sim vir a melhorar a compreensão e a facilitação na memorização das operações fundamentais na memória do aluno. 


\section{Conclusões}

Notamos a necessidade de oferecer aos alunos mais do que aulas padronizadas, e que há diversas maneiras de dá mais significado à Matemática, fazendo aulas criativas e desafiadoras. Observar o interesse dos alunos em aprender, e sentirem-se capazes de relacionar a aprendizagem escolar com o mundo fora da sala de aula é muito prazeroso para o professor. Com base nessa experiência vivenciada e nos relatos dos alunos, ficou claro o resultado na utilização de materiais concretos para o ensino das operações fundamentais, e a possibilidade das aulas de matemática serem mais interativas, de forma que os alunos possam participar do processo e tenham acesso aos

aspectos no desenvolvimento do conhecimento. Eles como principais participantes dessa criação se sentiram estimulados a fazer perguntas, questionamentos e discussões sobre a aplicabilidade do uso na matemática na prática e no seu dia-a-dia. Enfim, ressaltamos a extrema importância do professor como mediador facilitador na relação entre professor/aluno/conhecimento, para atingir o objetivo que é colocar em prática o que foi apresentado em sala de aula. $\mathrm{O}$ material concreto não substitui o professor e sim complementa sua proposta pedagógica e requer planejamento não se resumindo a uma simples atividade espontânea.

\section{Referências}

ALVES, Rubens. Cenas da Vida; Campinas - São Paulo; Papirus, 1997

BLACKBURN, Simon. Dicionário Oxford de Filosofia. Rio de Janeiro: Jorge Zahar Editor, 1997. BOYER, Carl Benjamin. História da matemática. São Paulo: Edgard Blücher, 1974. 488 p.

BRASIL, Parâmetros curriculares nacionais ( $5^{\mathrm{a}}$ a $8^{\mathrm{a}}$ série): matemática. Secretaria de Educação Fundamental. Brasília: MEC/SEF, 1997.

CARRAHER, Teresinha N.; SCHLIEMANN, A.; CARRAHER, D. Na vida dez na escola zero. São Paulo: Cortez, 2001.

D’AMBRÓSIO, Ubiratan. Da realidade à ação: Reflexões sobre educação Matemática. $2^{\mathrm{a}}$ ed. São Paulo: Summus, 1986.

RAFAELLA Pachêco, Ananda Venise. Problemas do dia a dia na aprendizagem: As operações fundamentais. Teresina: Semafis, 2013.

SIDNEY dos Santos. Metodos inovadores no ensino das operações fundamentais. Teresina: Semafis, 2013. 